\title{
La potencia crítica del arte: para pensar otras formas de construcción política
}

Juan Ignacio Fernandez

Universidad de Buenos Aires (Argentina)

ji.fernandez@live.com

Recibido 11/4/2017

Aprobado 13/6/2017

\section{Resumen}

La propuesta del presente artículo es la de acercarse a la tensión totalidad-particularidad, desde las perspectivas de Walter Benjamin, Theodor W. Adorno y Jacques Derrida, desarrollando ciertos conceptos referentes al arte, reflexionando acerca de cómo se tocan con las nociones de historia y tradición, y qué aportan al pensar la política y lo político. Se intenta revisar el papel que juega lo contingente respecto de tal oposición, y la consecuente obertura a pensar lo distinto, lo otro diferente, lo imposible como posibilidad. Reconociendo en el arte y su praxis, una potencia crítica que nos conduce al umbral de una manera diferencial y no demarcable, de pensar y reflexionar acerca de la política y lo político. Una no-determinación de lo estético como identidad con, como construcción de y como contenido político en sí mismo.

Palabras clave: estética - política - teoría del arte - historia (Thesaurus) - potencia crítica (palabras clave autor).

\section{Abstract}

The proposal of this article is to approach to the totality-particularity tension, from Walter Benjamin, Theodor W. Adorno and Jacques Derrida's perspectives, developing certain concepts related to art, reflecting on how they play with the ideas of history and tradition, and what they bring to think about politics and the polity. It tries to 
review the role of the contingent in respect of such opposition, and the consequent opening to think what is different, the different one, the impossible as a possibility. Recognizing in art and its praxis, a critical power leads us to the threshold of a differential and unremarkable way, of thinking and reflecting on politics and polity. A non-determination of the aesthetic as identity, as a construction of and as politician content in itself.

Keywords: aesthetics - politics - art theory - history (Thesaurus) - critical power (keywords author).

\section{Introducción}

Si de advertencias se trata, Walter Benjamin, experto en las habilidades de los avisos y las exhortaciones urgentes, no sólo (d)enuncia a mediados de la década de 1930 los problemas de la reproductibilidad técnica de la obra de arte, sino que también nos aconseja acerca de sus consecuencias. Pues bien, que la técnica y su dominio redunden en la profanidad estética de la modernidad y la cuestión aurática se rinda frente un valor para la exposición y la experiencia cotidiana, ponen su autonomía a debate, es decir: profanidad y técnica parecen atraerse y pueden ser una "combustión revolucionaria" emancipadora (para nada desestimable) de la vida capitalista propiamente dicha, sin embargo, la técnica también se encuentra a merced del fascismo y sus intentos de sujeción política, homogeneización y manipulación de las masas.

De manera similar, a propósito de la peligrosa opresión de la "totalidad social", que justamente ha caracterizado a los regímenes totalitarios del siglo XX, poniendo en entredicho las proyecciones de la modernidad capitalista, Theodor Adorno aporta, no sin suscitar otros entredichos ( $y$ en ocasiones con el propio Benjamin), la idea de negatividad también como posibilidad resistente y liberadora de la presión y el sofoco de lo socialmente dominante sobre la individualidad y los múltiples intentos por cambiar el orden impuesto por dicha totalización ${ }^{1}$. Es que el arte, a lo largo de su desarrollo histórico en general pero particularmente durante la modernidad, y en lo referente a cuestiones sociales y políticas, ha sabido ser un continente más o menos diáfano y controversial que ha suscitado, en su autenticidad, la apertura de nuevos espacios de experiencia ${ }^{2}$. En efecto, dicho elemento polémico no hace más que actualizarse en su seno, y si se realiza una aproximación al método de un autor más cercano en

\footnotetext{
${ }^{1}$ SCHWARZBOCK, Silvia. Adorno y lo político. Buenos Aires, Prometeo, 2008. P. 101.

2 ALBRECHT, Wellmer. "¿Podemos aún hoy aprender algo de la estética de Adorno?". En: Boletín de Estética. N 11, 2009. P. 9. Corresponde a la introducción y traducción de Sol Bidon-Chanal.
} 
el tiempo como Jacques Derrida, se notará el regreso sobre su potencia crítica y, consecuentemente, sobre la renovación y visibilización de la problematización social y política que alberga. En tal sentido, la reflexión acerca de las posibilidades que habilitan sus atributos críticos y sus efectos políticos transformadores goza de plena vigencia e invita a considerarla como una herramienta poderosa para la práctica política.

Es entonces que, a los fines de comprender cómo se gesta dicho potencial, la propuesta del presente artículo es la de acercarse a la tensión totalidad-particularidad, desde las perspectivas de Walter Benjamin, Theodor W. Adorno y Jacques Derrida, desarrollando ciertos conceptos referentes al arte, reflexionando acerca de cómo se tocan con las nociones de historia y tradición, y qué aportan al pensar la política y lo político. Se revisa el papel que juega lo contingente respecto de tal oposición, y la consecuente obertura a pensar lo distinto, lo otro diferente, lo imposible como posibilidad. Reconociendo en el arte, en su praxis, y en esa mentada potencia crítica que implica su reflexión, los elementos que nos conducen al umbral de una manera diferencial y no demarcable, de pensar y reflexionar acerca de la política y lo político. Una no-determinación de lo estético como identidad con, como construcción de y como contenido político en sí mismo.

En este orden de cosas, la reposición de estos problemas puede leerse, más o menos directamente, en las producciones teóricas de Albrecht Wellmer Sobre la dialéctica de modernidad y posmodernidad ${ }^{3}$ y su reflexión crítica acerca de la estética de Adorno ${ }^{4}$; en las tesis acerca del lenguaje en la obra de Benjamin de la autora chilena Elizabeth CollingwoodSelby ${ }^{5}$; y en La soberanía del arte, de Christoph Menke, que problematiza la experiencia estética en las perspectivas de Adorno y Derrida ${ }^{6}$. Así, uno de los supuestos que habitará la trastienda de este texto en su desarrollo, será la admisión (deliberada e intencional) de una cierta afinidad conceptual entre los autores, tomando como ejes generales las nociones de: traducción (W. Benjamin), negatividad y reconciliación (Th. W. Adorno), y deconstrucción (J.

\footnotetext{
${ }^{3}$ ALBRECHT, Wellmer. Sobre la dialéctica de modernidad y posmodernidad. La crítica de la razón después de Adorno. Madrid, Visor, 1993.

${ }^{4}$ ALBRECHT, Wellmer. "¿Podemos aún hoy aprender algo de la estética de Adorno?". En: Boletín de Estética (CIF). N¹1, 2009.

${ }^{5}$ COLLINGWOOD-SELBY, Elizabeth. Walter Benjamin: La lengua del exilio. Universidad de Chile, 1997. [Tesis doctoral]. Dirección: https://www.yumpu.com/es/document/view/28627519/walter-benjamin-lalengua-del-exilio-universidad-de-chile.

${ }^{6}$ MENKE, Christoph. La soberanía del arte. La experiencia estética según Adorno y Derrida. Madrid, Visor, 1997.
} 
Derrida). En tal sentido, no es casual la selección y problematización de estos conceptos como puntos de anclaje de este trabajo, en referencia a la potencia crítica que habita en la estética y su reflexión.

Complementariamente, otro supuesto que se deberá tener en cuenta, hace referencia a cómo concebiremos, en líneas generales, la distinción entre la política y lo político. Es así que, atendiendo al léxico heiddegeriano en forma similar al movimiento que realiza Chantal Mouffe $^{7}$, tendrá que entenderse a la primera, relativa al plano de lo óntico, como: toda actividad o acción llevada a cabo por uno o varios actores sociales, individuales o colectivos, dirigida a la consecución de sus intereses y al despliegue de sus intenciones en el ámbito de lo público, implicando diversas formas de participación y organización. Respecto de lo político, tendremos que pensarlo en referencia al plano ontológico, a lo esencial de la política y lo existencial de sus actores en cuanto tales, es decir: aquel aspecto de la vida política que fundamenta, en tanto que implica relaciones de poder y de fuerza determinadas (histórica, temporal, y espacialmente), la necesidad de la acción política que intenta organizarlas, atravesando, tanto el ámbito social como el económico.

En pocas palabras, en estos autores y sus propuestas teóricas, encontraremos los elementos comunes de una potencia estético-crítica al servicio del pensamiento y las prácticas dinamizadoras de los problemas políticos, de las formas de participación política, y de los sujetos que los/las experimentan.

\section{Benjamin: la traducción y la fuerza de lo no dicho}

En lo que respecta a su concepto de $\operatorname{traducción}^{8}$, Benjamin se encarga de advertir, en una reflexión acerca de su servicio, sobre la eventualidad de arribar a una concepción frívola,

\footnotetext{
${ }^{7}$ MOUFFE, Chantal. En torno a lo político. Buenos Aires, Fondo de Cultura Económica, 2011. Pp. 15-16.

${ }^{8}$ La selección de este concepto responde a la intención que sea pensado (por el lector) en su movimiento. Como una "estructura" en la que se da un movimiento de discontinuidad entre dos lenguajes, haciendo saltar los diversos elementos que habitan una obra, a la vez que conectándolos "suprahistóricamente". Es decir, si en "La tarea del traductor" Benjamin hace un elogio de los románticos como pioneros en la mención de una "vida de la obra" y su prueba más acabada es la traducción, la forma de esta traducción implica la vida del original, una vuelta hacia él, y un lazo con su supervivencia. BENJAMIN, Walter. Conceptos de filosofía de la historia. Buenos Aires, Agebe, 2011.
} 
inconsistente, y superficial ${ }^{9}$ del término, la cual debe ser evitada. De esta forma, al interrogarse sobre la función de la traducción, afirma que: "sirve pues para poner de relieve la íntima relación que guardan los idiomas entre si” $^{10}$. A simple vista, esta afirmación parece ser sencilla y digerible, pero es dueña de una complejidad, un espesor y una intensidad que intentaremos desplegar en los párrafos venideros. Para ello, debemos comenzar por entender cómo concibe este autor al lenguaje.

Una aproximación inicial a la concepción benjaminiana del lenguaje, nos enfrenta a una primera y certera sentencia: "toda comunicación de contenidos espirituales es lenguaje"11. Esto da la pauta de que la existencia del lenguaje se extiende a todo, es decir, a toda entidad de la naturaleza (animada o inanimada), ya que está en su esencia la comunicación de su propio contenido espiritual en la expresión. De esta manera, Benjamin no limita el lenguaje sólo al ámbito de la expresión de la vida espiritual humana. A su vez, distingue entre ser lingüístico y ser espiritual, siendo siempre el primero expresión inmediata del segundo, es decir, comunicándose el ser espiritual en el lingüístico. Esta inmediatez no descansa en una identidad exterior del ser espiritual respecto del lingüístico, sino que, "lo que en un ser espiritual es comunicable es su ser lingüístico"12, éste es aquello en lo cual se comunica (a sí mismo), es su lenguaje. En tal sentido, el lenguaje es un continente ${ }^{13}$ : "El ser espiritual se comunica en y no a través del lenguaje ${ }^{\prime 14}$. Por esto, cada lenguaje tiene una infinitud

Asimismo, en tal movimiento reflexivo, se pueden traspasar dos "centros reflexivos", un hombre y una cosa, un traductor y una obra, e inmanentemente, se conectan en el absoluto. ABADI, Florencia. "La teoría de la crítica de arte: la lectura de Benjamin del romanticismo alemán". En: Boletín de Estética (CIF). N 12. Buenos Aires, 2009.

${ }^{9}$ En "La tarea del traductor", Benjamin hace una distinción entre traducción y "mala traducción”, y así, reconoce la existencia de los "malos traductores". Representando una forma errónea de concebir la traducción, al referir a aquellas traducciones (y sus correspondientes traductores) que tienen sólo por objetivo asir y transmitir el sentido del texto; situación la cual, encarna una empresa imposible respecto de los términos en los cuales este autor concibe al lenguaje. En tal caso, este intento erróneo de traducción, es pensado en la inconsistente concepción burguesa de la lengua, donde el lenguaje, justamente, es entendido como una mera convención arbitraria entre los hombres. Op. cit. BENJAMIN, Walter. Conceptos de filosofía de la historia. Buenos Aires, Agebe, 2011. Pp. 17-31.

${ }^{10}$ Op. Cit. BENJAMIN, Walter. Conceptos de filosofía de la historia. P. 20.

${ }^{11}$ Ibíd. P. 33.

${ }^{12}$ Ibíd. P. 35.

${ }^{13}$ Op. Cit. COLLINGWOOD-SELBY, Elizabeth. Walter Benjamin: La lengua del exilio. P. 19.

${ }^{14}$ Op. Cit. BENJAMIN, Walter. Conceptos de filosofía de la historia. P. 35. 
específica, la cual, es condición de cada ser lingüístico como tal, como esencia lingüística. Razón por la que el lenguaje no puede ser otra cosa que experiencia y, como tal, se vive.

Profiriendo esta noción de lenguaje como continente, como ser lingüístico de todo ser espiritual, logra afirmar que aquel atañe tanto a las cosas como al hombre. Sin embargo, como (la lengua de) los hombres habla(n) en palabras, a diferencia (de la lengua) de las cosas: "el hombre comunica por lo tanto su propia esencia espiritual (en la medida en que es comunicable) nombrando todas las otras cosas. [...] La esencia lingüística del hombre es por lo tanto nombrar las cosas"15. Por consiguiente, es en (y no a través de) el nombre donde se comunica de manera absoluta el lenguaje mismo: "en el nombre la esencia espiritual que se comunica es el lenguaje" ${ }^{16}$, es decir, el lenguaje humano, ya que a él pertenece aquel. Es por ello que el ser espiritual del hombre es el único enteramente comunicable, y así, "sólo el hombre tiene lenguaje perfecto en universalidad e intensidad" ${ }^{17}$ como correspondencia constante del nominante y del nominado, como lenguaje propiamente nominal. De ahí que el lenguaje humano guarde una comunión inmaterial y puramente espiritual con las cosas, a diferencia del lenguaje imperfecto de las cosas, las cuales son mudas y sólo pueden relacionarse entre ellas materialmente.

En esta línea de pensamiento y en consonancia con el relato bíblico, Benjamin afirma, en primera instancia, que el lenguaje humano es el reflejo del verbo divino en el nombre, siendo un eco o una constancia de la Creación. Cuestión que podría pensarse como una reverberación del arkhé o, mejor dicho, como un arkhé de la reverberación que representa la lengua humana, dado que el nombre refleja la acción creadora. En definitiva, describe un lenguaje humano de orden limitado como latencia de un lenguaje paradisíaco que es dueño de una infinitud absoluta. Pues bien, en Dios el nombre es creador y conocedor, crea a todos los seres, y el hombre es aquel al que Dios no nombra, pero al cual da el "poder nombrar" las cosas creadas. De esta manera, hay una comunidad que todo lenguaje humano guarda con Dios, que descansa en el nombre que, como palabra humana de lo creado por éste, es receptividad del lenguaje de las cosas que irradia mudamente la palabra (divina): "el nombre que el hombre da a la cosa depende de la forma en que la cosa se comunica con él"18; es una

\footnotetext{
${ }^{15}$ Ibíd. P. 36.

${ }^{16}$ Ibíd. P. 37.

${ }^{17}$ Ibíd. P. 38.

${ }^{18}$ Ibíd. P. 44.
} 
escucha del hombre que responde al llamado de las cosas, y en tanto que responde a ese llamado (de los otros), es. Lo que lo lleva a concluir por tanto, que el nombrar es una traducción: "es la traducción del lenguaje de las cosas al lenguaje de los hombres" ${ }^{19}$, de un lenguaje imperfecto a un lenguaje que aporta conocimiento, y que resulta del cumplimiento por parte del hombre de la tarea de nombrar las cosas que el Creador ("dueño" de un lenguaje puro) le ha legado, quedando de manifiesto en ese deseo de ser otro, en esa llamada.

Pero hay algo que ocurre con esta receptividad. Esta escucha del susurrar de la palabra divina en las cosas se ve perturbada, algo ocurre con el lenguaje (de los) humano(s), se produce un hiato, un daño insalvable que trastoca la situación paradisíaca. Es entonces que "tropezamos" con: La Caída, el pecado original del relato bíblico; momento en el cual la "palabra que juzga expulsa a los primeros hombres del paraíso" ${ }^{20}$, el nombre se daña, y su pureza eterna ya no permanece intacta. Este es el material genético de la palabra humana: el nombre se separa de las cosas y ya no es receptivo de su lenguaje mudo, y así, la escucha es reemplazada por el juicio que, en tanto saber del bien y del mal, se separa del nombre que refleja el verbo divino y da nacimiento a la abstracción, motivo por el cual, el hombre hace del lenguaje un medio, un signo (instalándose lo que, retomando a Kierkegaard, nuestro autor berlinés reconoce como: charla ${ }^{21}$ ). De este modo, en la lengua humana media la intención como efecto del juicio, "la palabra debe comunicar algo (fuera de sí misma)”22:

[A]penas el hombre cae del estado paradisíaco en que conocía un solo lenguaje. [...] cada conocimiento vuelve a diferenciarse infinitamente en la variedad de las lenguas y debía necesariamente diferenciarse, en un estadio inferior como creación en el nombre ${ }^{23}$.

\footnotetext{
${ }^{19}$ Ibíd. P. 44.

${ }^{20}$ Ibíd. P. 47. propiciar la reflexión del ser que, justamente, evita la charla.

${ }^{22}$ Op. Cit. BENJAMIN, Walter. Conceptos de filosofía de la historia. P. 47.

${ }^{23}$ Ibíd. P. 46.
}

${ }^{21}$ La charla, así entendida, no permite el intercambio entre los seres humanos porque el discurso se agota en una palabra que no dice nada. Quizá, una forma gráfica y efectiva de pensarlo sea imaginar un "ruido" que distorsiona el diálogo, que tiende a abolir la distinción callar-hablar (entre el silencio y el habla) propia del diálogo que permite, mediante la "práctica" silenciosa, recibir la palabra del otro y 
Así resulta la pluralidad de los lenguajes humanos, una multiplicidad de traducciones; deja de existir ese estado paradisíaco donde ser y lengua eran uno y sí mismo, ocurre que: "después de la caída [...] no había más que un paso para llegar a la confusión de los lenguajes" ${ }^{24}$. Pues bien, dicha instancia, no es otra cosa que "la segunda caída: la caída babélica, la que da lugar a la multiplicidad de las lenguas" 25 , de la cual no hay retorno alguno. Este es el umbral o la antesala directa "a la superdenominación o determinación excesiva que rige en la trágica relación entre los lenguajes de los hombres parlantes" ${ }^{26}$; sobredeterminación que, lógicamente, rige también sobre los objetos, como sobredenominación de las cosas.

En resumidas cuentas, en la concepción benjaminiana del lenguaje, "todo lenguaje superior es traducción del inferior, hasta que se despliega, en la última claridad, la palabra de Dios, que es la unidad de este movimiento lingüístico" ${ }^{27}$ : del lenguaje de las cosas al de los hombres y desde éste al lenguaje puro de Dios. Sin embargo, debido a una escisión de ser y lengua, todo lenguaje humano es parte y no unidad, es incompleto, queda inconcluso, está fisurado. Luego de La Caída ya no hay plenitud y conclusión como lo había en el lenguaje puro de Dios sino falta. Lo cual, no sólo deja de manifiesto la imposibilidad del deseo de volver a la unidad, al lenguaje puro, de retornar al origen, sino que muestra el parentesco entre los múltiples lenguajes de los hombres, y también el surgimiento de la apelación por parte del lenguaje humano a un significado. El lenguaje de los hombres, o mejor dicho, los múltiples lenguajes de los hombres, se presentan como los fragmentos de un lenguaje puro y pleno, que es identidad de ser y lengua, un lenguaje en el cual, no hay nada fuera del nombre (de Dios). En definitiva: no hay unidad, no existe un contenido que una lengua pueda comunicar a otra en una continuidad ininterrumpida de tipo "naturaleza-hombre-Dios".

Después de La Caída, si ya adentrados en la concepción del lenguaje que propone Benjamin reeditamos el interrogante acerca de la traducción, enseguida encontramos la idea de una relación íntima entre los lenguajes, una afinidad que queda de manifiesto en la traducción: “las lenguas no son extrañas entre sí, sino a priori [...] mantienen cierta semejanza

\footnotetext{
${ }^{24}$ Ibíd. P. 48.

${ }^{25}$ Op. Cit. COLLINGWOOD-SELBY, Elizabeth. Walter Benjamin: La lengua del exilio. P. 47.

${ }^{26}$ Op. Cit. BENJAMIN, Walter. Conceptos de filosofía de la historia. P. 50.

${ }^{27}$ Ibíd. P. 51.
} 
en la forma de decir lo que se proponen" ${ }^{28}$, compartiendo un deseo de plenitud, de volver al lenguaje puro, al origen. Sin embargo, no debemos pensar la semejanza en un sentido convencional del término, ya que:

[L]a traducción ha de experimentar de manera especial la maduración de la palabra extranjera, siguiendo los dolores de alumbramiento de la propia lengua. [...] no guarda relación alguna con la vaga semejanza que existe entre la copia y el original. De esto se infiere que el parentesco no implica forzosamente la semejanza ${ }^{29}$.

De ahí que quede de manifiesto la contradicción de la traducibilidad, a saber: por un lado, el parentesco mencionado, y por otro, un abismo, una distancia insalvable que hace imposible su traducción. En pocas palabras: un dilema entre libertad y fidelidad.

A partir de este contraste entre cierta familiaridad y cierta distancia insalvable, se puede comenzar a trazar una "radiografía" de la traducción y las implicancias de su práctica. Principalmente, implica la existencia de un original, es decir, la existencia de un original para su traducción, y la relación de dos lenguajes que se tocan, se rozan, manteniendo entre sí una relación de complementariedad en pos de un deseo común de (retorno al) lenguaje puro que sólo es posible en la diferencia mutua. En este sentido, debemos tener en cuenta un supuesto de esta relación: "ninguna traducción sería posible si su aspiración suprema fuera la semejanza con el original. Porque en su supervivencia [...] el original se modifica" ${ }^{30}$, y la lengua a la que se traduce también sufre cambios en el tiempo. Este supuesto, junto con la referencia acerca de la afinidad entre los lenguajes, ponen de manifiesto dos cuestiones: por un lado, que la traducción no debe identificarse con el sentido del original, sino que debe, prescindiendo de éste, reconstituir el original, siendo de esta manera, fiel a sí misma como lengua; y, por otro lado, que los significados de las lenguas se encuentran en una transformación continua. De esta manera, la traducción tendrá que poner de manifiesto aquello intangible en el original y evidenciarlo, aquello que se oculta en él, eso que es incontenible. Aquello no dicho que se

\footnotetext{
${ }^{28}$ Ibíd. P. 20.

${ }^{29}$ Ibíd. P. 22.

${ }^{30}$ Ibíd. P. 21.
} 
encuentra más allá de la intención. Por lo cual, el traductor debe practicar una suerte de escucha del roce de las lenguas, y estar expectante al eco del original.

De esta manera, si aquella complementariedad mencionada, propia de la multiplicidad de las lenguas que afecta tanto a original como a la/s traducción/es, pone de manifiesto la imperfección, la falta, la fisura en el original respecto de su deseo por decir pleno que implica el deseo de ser otro inaprehensible y que nunca se presenta, entonces, el original, como lenguaje, en su intento por decir plenamente, por ser redimido, exige la traducción. Es decir que, la obra primigenia, se sirve de ella para poner de manifiesto su particularidad como parte de una plenitud fragmentada que no puede decirse por sí sola, quedando a la vista su constante transformación: "las traducciones no son las que prestan un servicio a la obra, [...] si no que más bien deben a la obra su existencia. La vida del original alcanza en ellas su expansión póstuma más vasta y siempre renovada" ${ }^{31}$. En este sentido, pensar la traducción es pensar La Caída y Babel, es pensar en la diseminación de ese lenguaje puro en fragmentos que ocultan en sí mismos algo de esa pureza, de esa latencia del origen que, sólo es perceptible como particular, en la relación de los lenguajes, en el roce de los lenguajes, abriendo así, en el movimiento de su práctica, una multiplicidad renovable e ilimitada de posibilidades.

\section{Adorno: negatividad y reconciliación}

Ante todo, en la teoría estética adorniana, la obra de arte se concibe como algo escindido que, por un lado, tiene un momento mimético material que supone violentar la naturaleza por parte del ser humano como afirmación del espíritu, y, por otro, uno formal que implica el concepto (lenguaje) y necesita de él. Asimismo, podemos tener la certeza de que toda obra de arte nace en un contexto social y, por lo tanto, es parte del mismo. Pues bien, en este sentido, el arte moderno es autónomo, es decir, es independiente de otros discursos y funciones culturales y sociales. Esta autonomía es un logro histórico que la diferencia del arte premoderno, la cual, ligada a una idea de destreza o facultad, era más obvia en su función. De esta forma, abre el interrogante acerca de su función social, y su respuesta es contundente: "Si se puede atribuir a las obras de arte una función social, es su falta de función"32; sólo así, separándose radicalmente de cualquier función social, puede decir algo crítico de la sociedad

\footnotetext{
${ }^{31}$ Ibíd. P. 20.

${ }^{32}$ ADORNO, Theodor. Teoría Estética. Madrid, Akal, 2004. P. 300.
} 
de la cual surge. Y al afirmar que: "El arte es la promesa de felicidad que se rompe" ${ }^{33}$, da cuenta de un permiso crítico aunque ciertamente limitado que nos otorga a través de su forma y su aspecto ficticio, sobre el pensar las posibilidades referentes a la realidad empírica.

Consecuencia de dicha autonomía es que podemos tratar de lo nuevo, este es nuestro punto de partida como lo característico de la modernidad. ¿Qué es lo nuevo? Justamente, en la reflexión estética de Adorno, la categoría de lo nuevo es lo que define el arte moderno en tanto que tal. Es aquello que rompe con lo empírico y con la tradición y su normativa, transgrede las formas de comprensión establecidas, y por lo tanto, también ata estéticamente a sociedad e individuo. "Lo nuevo es el anhelo de lo nuevo, pero apenas lo nuevo mismo: de esto adolece todo lo nuevo. Lo que se siente a sí mismo como utopía, es algo negativo frente a lo existente, y está sometido a lo existente" ${ }^{34}$. Así, lo nuevo estético es en su transgresión, negatividad $^{35}$; y en ello radica la definición estética (la diferencia entre lo estético y lo noestético). La negatividad que, como se deduce de las líneas precedentes, presupone a la mencionada autonomía, existe en tanto que hacemos referencia a las certezas de otros discursos, pero también es posible que el arte provoque la subversión de estos últimos y, en tal sentido, haga una proclama de su soberanía. Sin embargo, "el arte tampoco es capaz de concretar la utopía; ni siquiera negativamente" ${ }^{36}$ ya que, en tal caso, encontraría su fin temporal. Quiere y tiene que ser, pero no puede cumplir su utopía: "los antagonismos reales no resueltos no se pueden solucionar ni siquiera imaginariamente [...] Las obras de arte tienen que presentarse como si lo imposible fuera posible..." ${ }^{37}$. Es decir, si bien el arte moderno es autónomo como resultado de "no tener función social", es a la vez cultural, es un producto del espíritu humano, formal, y en tanto que tal, imaginario y ficticio, escindido de la realidad empírica plural que representa la naturaleza. Y así, sólo mediante lo negativo, dice lo indecible, lo imposible, aunque sin intervenir en el dominio de la realidad empírica.

Con esta lógica negativa, Adorno reconoce que el arte moderno es arte auténtico y verdadero en tanto que su autonomía garantiza su propia organización, producción y

\footnotetext{
${ }^{33}$ Ibíd. P. 184.

${ }^{34}$ Ibíd. P. 50.

${ }^{35}$ En este párrafo y el subsiguiente se hace referencia a la sistematización que realiza Wellmer sobre la noción de negatividad, pero se invierte el orden de aparición en su texto. ALBRECHT, Wellmer. "¿Podemos aún hoy aprender algo de la estética de Adorno?". En: Boletín de Estética. N 11, 2009. P. 21.

${ }^{36}$ Op. Cit. ADORNO, Theodor. Teoría Estética. P. 51.

${ }^{37}$ Ibíd. P. 226.
} 
desarrollo, pero nos advierte acerca de que lo verdadero en el arte es algo que no existe: "el contenido de verdad no puede ser algo hecho"38. Por consiguiente, luego de afirmar que el arte busca lo otro que es plural, que no tiene unidad y es identificado por la razón con la palabra "naturaleza", sostiene que la verdad de la obra de arte es la apariencia de lo que no tiene apariencia, y se encuentra en la historia en tanto que cristalización en la obra. De esta manera, concluye en lo que podemos leer como un mapa mudo de lo negativo: "Los elementos de eso otro están reunidos en la realidad, sólo tendrían que aparecer (ligeramente desplazados) en una constelación nueva para encontrar su lugar correcto" ${ }^{39}$. Con este razonamiento, la (teoría de la) imitación parece invertirse, ya que por el concepto utópico que la hace hermanarse con la filosofía, "el arte es mimesis espiritualizada"40 y enseña tal desplazamiento a la realidad, indicando la posibilidad de existir de lo no existente: "La realidad de las obras de arte habla a favor de la posibilidad de lo posible. [...] su aspecto ficticio consiste en que mediante su existencia establece que el límite está superado” ${ }^{41}$.

Dado el movimiento descripto en el párrafo precedente, el arte parece poner en jaque a la supremacía de la totalidad, dando espacio a lo múltiple y a lo particular desde las obras, como autoconciencia crítica de determinadas condiciones históricas. Esta es una clara consecuencia que resulta de su mentada antinomia, o mejor dicho, de su determinación bipolar $^{42}$ (entre) autonomía-soberanía, de la cual se desprende todo su poder subversivo, incomodando a la razón y a los discursos no-estéticos al poner de manifiesto sus contradicciones y sus caracteres contingentes. En este sentido, Adorno tiene la estrategia metodológica que le permite atenuar la identificación de lo universal y lo particular como causa fundante de la opresión de la totalidad social sobre la particularidad individual. Es entonces que, allí donde el peso de la totalidad pervive en la interioridad de los individuos como partes y no quiere lo heterogéneo, en la realidad empírica donde se impone violentamente a los objetos la identidad con el sujeto: "La identidad estética ha de socorrer a

\footnotetext{
${ }^{38}$ Ibíd. P. 178.

${ }^{39}$ Ibíd. P. 180.

${ }^{40}$ Op. Cit. ALBRECHT, Wellmer. Sobre la dialéctica de modernidad y posmodernidad. La crítica de la razón después de Adorno. Pp. 18-19.

${ }^{41}$ Op. Cit. ADORNO, Theodor. Teoría Estética. P. 180.

${ }^{42}$ Op. Cit. MENKE, Christoph. La soberanía del arte. La experiencia estética según Adorno y Derrida. Pp. 13-20.
} 
lo no idéntico que es oprimido en la realidad por la imposición de la identidad”43; quiere lo no idéntico, esa es su identidad. Una contrapresión ${ }^{44}$ a la presión del todo social, tal es la característica de la modernidad y su arte. De este modo, si bien el arte al ser forma es también culpable de la violencia que ejerce, nos recuerda aquello que oprime el espíritu, he ahí la paradoja que resulta de su contenido negativo.

Pues bien, imposición y opresión, dan cuenta del elemento irreconciliable que yace entre la totalidad social y lo particular individual. Por lo tanto, si pensamos en la unidad extraestética de lo múltiple, en lo homogéneo, no podemos dejar de pensar, justamente, en la violencia que ejerce el espíritu sobre lo plural y diverso. No obstante:

La unidad estética de lo múltiple aparece como si no hubiera hecho violencia a lo múltiple, sino que hubiera sido conjeturada a partir de ello. De este modo, la unidad (que hoy como siempre es lo escindidor) pasa a la reconciliación. [...] En las obras de arte, el espíritu ya no es el viejo enemigo de la naturaleza. Se calma hasta convertirse en lo reconciliador ${ }^{45}$.

En efecto, el arte hace creer que la reconciliación ya existe. La reconciliación es su propio comportamiento, es el arte mismo que se identifica con lo no idéntico al quererlo. En tal sentido, el arte anticipa lo que podría ser y no es y sólo de esa manera es sí misma. De ese modo resiste y puede potencialmente transformar por medio de sus (im)posibles, la opresión de la totalidad que nada tiene de natural, en favor de una reconciliación con la naturaleza por parte de los sujetos. Entonces, mientras procura la reconciliación que, ciertamente, guarda coherencia con la transitoriedad del mundo y su contingencia, está asistiendo a la verdadera historia para poder liberarse de la historia del espíritu cosificante (de la racionalidad instrumental) que la petrifica.

\footnotetext{
${ }^{43}$ Op. Cit. ADORNO, Theodor. Teoría Estética. P. 13.

44 "La punta que el arte vuelve contra la sociedad es, a su vez, algo social, contrapresión contra la gravosa presión del social body". Ibíd. P. 51. En este pasaje, Adorno menciona también, la hermandad entre las fuerzas productivas extraestéticas e intraestéticas, poniendo de manifiesto el potencial políticamente desencadenante que puede aportar el arte.

${ }^{45}$ Op. Cit. ADORNO, Theodor. Teoría Estética. P. 182.
} 


\section{Derrida: dislocación de los confines de la tradición}

Ante todo, vale aclarar que la propuesta de la deconstrucción no se ciñe exclusivamente a textos de una temática o disciplina en particular, sino que implica en su empresa textos toda índole (científicos, literarios, filosóficos, etc.), es decir: escritura. En segundo lugar, y como punto de partida, es necesario comprender que el diagnóstico derrideano de la tradición Occidental supone: por un lado, la existencia de una primacía del ahora como privilegio del instante presente, del cual dependen el pasado y el futuro, y que se sostiene según una determinada sucesión espacial-lineal; y, por otro lado, tiene en consideración a la escritura como un suplemento de la palabra, como un instrumento secundario de la voz. Por consiguiente, nos encontramos con dos combinaciones, a saber: 1) la amalgama de una idea de sucesión que potencia la noción de origen pleno (como búsqueda de una supuesta plenitud perdida, por allá, por "los orígenes de la vida") y el concepto de teleología, como privilegio casi absoluto de la linealidad:

[L]a linealidad del lenguaje va acompañada del concepto vulgar y mundano de la temporalidad (homogéneo, dominado por la forma del ahora y el ideal del movimiento continuo, recto o circular) del que Heidegger demuestra que determina desde el interior toda ontología, desde Aristóteles hasta Hegel ${ }^{46}$.

Y además, 2) el conjuro de un privilegio por la voz debido a su proximidad con el pensamiento y la interioridad de la conciencia que dice un sentido presente en el logos:

[E]l logos no puede ser infinito y presente consigo, [...] sino a través de la voz: orden de significante por medio del cual el sujeto sale de sí hacia sí, no toma fuera de él el significante que emite y lo afecta al mismo tiempo. [...] Ella se vive y se dice como exclusión de la escritura, o sea del requerimiento de un significante 'externo', 'sensible', 'espacial' que interrumpe la presencia consigo ${ }^{47}$.

\footnotetext{
${ }^{46}$ DERRIDA, Jacques. De la gramatología. México, Siglo XXI, 1986. P. 114.

${ }^{47}$ Ibíd. P. 130.
} 
En este sentido, hay una lógica del discurso que caracteriza a la tradición del pensamiento occidental que encuentra su arquetipo en la episteme platónica, una serie de oposiciones operativas que surgen de la contraposición realidad/signo y sirven a la repetición de esta lógica jerárquica de presencia (logos) sobre ausencia, propiciando el ámbito para sostener siempre una pérdida de racionalidad: inteligible/sensible, dentro/fuera, significado/significante, es decir, logos (presencia)/escritura (representación). Es entonces que, la degradación y violencia ejercidas sobre la escritura por parte de la tradición occidental, redundan en una artimaña de ésta que se despliega en dos dimensiones: acusar al signo de la violencia que ella misma aplica para privilegiar al logos, y reducir a la identidad la diferencia entre éste y su/s otro/s (una totalidad pura y racional de un lado, y una pluralidad que, en tanto no idéntica, es irracional, del otro). Así, esta astucia se nutre de una ilusoria identidad que, entre un buscado y ansiado fundamento único (originario) y su alteridad, sirve a los fines de su sostenimiento.

A partir de este razonamiento, Derrida denuncia una metafísica de la presencia que descansa en el privilegio de la voz por proximidad esencial al ser: logocentrismo. Es decir: toda la potencia del origen como verdad ansiada, deseada y creadora de sentido, que se mueve en forma subrepticia pero que sin embargo está ahí, a la vista, esperando el intento inútil de aprehensión por parte de la escritura que no es más que una mera representación. Es evidente que esta concepción es puro Idealismo para nuestro autor argelino-francés, es un "logocentrísmo que es también un fonocentrismo: proximidad absoluta de la voz y del ser, de la voz y del sentido del ser, de la voz y de la idealidad del sentido" ${ }^{48}$.

Reconocida esta diferencia (que devendrá differance) y reconocido el intento de la tradición occidental por borrarla a manos de la identidad con el logos; Derrida afirma que (en el discurso de las ciencias humanas y la filosofía occidental):

[E]I concepto de estructura e incluso la palabra estructura tienen la edad de la episteme, [...] y que hunden sus raíces en el suelo del lenguaje ordinario, al fondo del cual va la episteme a recogerlas para traerlas hacia sí en un desplazamiento metafórico $^{49}$.

\footnotetext{
${ }^{48}$ Ibíd. P. 18.

${ }^{49}$ DERRIDA, Jacques. La escritura y la diferencia. Barcelona, Anthropos, 1989. P. 383.
} 
De esta manera, pone de manifiesto dos cuestiones: a) que la estructura ( $y$, por lo tanto, su estructuralidad) siempre ha funcionado, y b) que en ese funcionamiento siempre ha sido neutralizada otorgándosele un centro, un origen fijo, un principio organizador, que limita su juego. Un centro que es la clausura de la estructura, que cierra el juego que él mismo abre, que crea una certeza que sirve al dominio de la angustia, que está dentro y fuera de la estructura, que puede ser llamado origen y fin, que se repite, que es sustituido, que se transforma; pero que, por sobre todas las cosas, expresa el vigor de un deseo y tiene la forma de una presencia. Así, "toda la historia del concepto de estructura [...] debe pensarse como una serie de sustituciones de centro a centro" ${ }^{150}$, historia de tales desplazamientos (metáforas y metonimias), que no es otra que la historia de Occidente: "la determinación del ser como presencia en todos los sentidos de esa palabra" ${ }^{51}$.

En este movimiento, la episteme, con lo que parece ser una fuerza centrípeta, ha sabido atraer hacia sí al concepto de estructura mediante movimientos metafóricos en el lenguaje. Por esta razón, Derrida vuelve sobre la lingüística saussureana, que entiende al lenguaje como un sistema de signos que genera su propio sistema de diferencias y que además deja de manifiesto la naturaleza arbitraria (asignación del significado al significante) y teológico-metafísica del signo, para reconocer el mismo arquetipo. Es la misma lógica logocéntrica, es decir que si el signo se compone de significado y significante: el primero sería privilegiado frente al segundo por su proximidad con el logos, es decir, con la razón como palabra hablada; y el segundo una mera representación del primero, quedando a la vista su dependencia metafísica. Por tal motivo, hay que sospechar del mismo concepto de signo que no hace más que servir a la metafísica de la presencia. Por otra parte, los significantes son entonces la ausencia de la presencia, la presencia diferida, por lo cual, todo signo es repetible en ausencia de una intención de comunicación, ya que todo significado, que descansa en una imagen-acústica, en una impronta psíquica, está en posición de significante en el momento que pertenece a una cadena que forma un sistema de significaciones, quedando desestimada cualquier supremacía de uno sobre otro.

Ahora bien, es necesario preguntarse acerca de cuál es el carácter de esta ausencia que interviene en el funcionamiento de la escritura. En primer lugar, es ausencia de (o anticipo al) destinatario: “Un signo escrito se adelanta en ausencia de destinatario. [...] en el momento en que yo escribo, el destinatario puede estar ausente de mi campo de percepción

\footnotetext{
${ }^{50}$ Ibíd. P. 385.

${ }^{51}$ Ibíd. P. 385.
} 
presente" ${ }^{\prime \prime 2}$. Dicha diferencia (o desfasaje) es referida a un cierto "absoluto de la ausencia", debe ser reiterable, repetida por otros, esto la hace estructuralmente legible, esto la hace escritura. En este sentido, es esta (y toda) iterabilidad la que habilita cierta posposición de sentido y la que le da el permiso para acuñar el concepto de (la) differance. En segundo lugar es ausencia de escritor: "Escribir es producir una marca que constituirá una especie de máquina productora a su vez, que mi futura desaparición no impedirá que siga funcionando y dando, dándose a leer y a reescribir ${ }^{\prime \prime 3}$. Es una ausencia que se produce y se pierde en el texto: "significa sin duda el no-lugar y la errancia, la ausencia de caminos prescritos" ${ }^{54}$; así, la escritura, la estructura de lo escrito, es permanencia (más allá de la presencia del querer decir) y ruptura de contextos, además que permiso para significar. Es decir, por un lado, hay ausencia de referente que es posibilidad de iterabilidad (del signo) y, por otro, ausencia de significado que es perceptible en (tres niveles: la vacuidad del signo, la privación de significación objetiva y) el concepto de agramaticalidad que rescata de Husserl, para el cual, la citacionalidad es su “aparición":

Todo signo, [...] puede ser citado, puesto entre comillas; por ello puede romper con todo contexto dado, engendrar al infinito nuevos contextos, de manera absolutamente no saturable. [...] no hay más que contextos sin ningún centro de anclaje absoluto ${ }^{55}$.

Además, si la firma del autor, en tanto que posibilidad de ligadura con la fuente, intentara la "reproductibilidad pura de un acontecimiento puro" ${ }^{56}$ de firma, sería otra pretensión de trascendentalidad (logocéntrica), y sólo dejaría de manifiesto la imposibilidad de su intento, ya que sólo puede existir como repetición o presencia diferida. Concluye por tanto, que el sistema de presencia y verdad es una consecuencia del logocentrismo, y en este sentido, la escritura

\footnotetext{
52 DERRIDA, Jacques. Firma, acontecimiento, contexto. Universidad de Montreal, 1971. P. 9. [Ponencia]. Dirección: http://www.ddooss.org/articulos/textos/derrida firma.pdf.

${ }^{53}$ Ibíd. P. 10.

${ }^{54}$ Op. Cit. DERRIDA, Jacques. La escritura y la diferencia. P. 99.

${ }^{55}$ Op. Cit. DERRIDA, Jacques. Firma, acontecimiento, contexto. P. 15.

${ }^{56}$ Ibíd. P. 25.
} 
excede al intento de comunicar cualquier sentido trascendental: "La escritura se lee, no da lugar en 'última instancia', a un desciframiento hermenéutico, a la clarificación de un sentido o una verdad" ${ }^{\prime 27}$.

Por tal motivo, la escritura, la estructura de la escritura (su estructuralidad) parece ser lo que organiza a un sistema de referencias infinitas como es el lenguaje. Un sistema de infinitas reminiscencias que Derrida llama huellas. Tal es la ilusión del logos: la identidad entre el decir y el querer decir. Sin embargo, como la/s huella/s implican la presencia diferida, dejan de manifiesto aquello que se resiste en toda estructura metafísica, aquello que no quiere la palabra plena, el punto de fuga, la fisura que se intenta (inútilmente) borrar, lo que no permite su identidad con lo otro. Este es el juego de ausencia y de presencia siempre, "un juego de sustituciones infinitas en la clausura de un conjunto finito" ${ }^{58}$, un desborde, un exceso de significación que es condición del pensamiento simbólico ante la imposibilidad de clausura del sentido, ante esa ausencia de centro u origen que es su motor. Por tanto, si pensamos una respuesta acerca de qué trata la deconstrucción, podemos arribar a: una estrategia que, de por sí, habita en el texto; una radicalización de este doble juego de escritura y lectura, de lectura y escritura, de este juego de la differance, de la citacionalidad, del equívoco, que nos demuestra que la escritura es una práctica sin fin de devenir los posibles confines de lo otro.

\section{El arte y lo impensado: significación e historia}

Primeramente, si hay un elemento conceptualmente afín a destacar entre estos autores, es un esfuerzo por "salvar" el concepto de historia de las "garras" de la tradición occidental, como si fuera una decisión que tiene por objeto invitar, cuando menos, a pensar lo imposible como posibilidad. Un temerario intento por poner de manifiesto a cada instante, la ocasión de una transformación radical, explotando lo impensado, lo otro no dicho, como posible porvenir. Esta pretensión no se agota en un simple pensar contrafáctico, sino que implica hacer temblar (en términos derrideanos) las categorías tradicionales a través de las cuales pensamos lo fáctico y lo contrafáctico. Es un movimiento que prepara los cimientos para dicho salvataje, disponiéndonos a una forma renovada de pensar la noción de historia, concientizándonos acerca de ciertos vicios, tabúes y pretensiones de la tradición, y

\footnotetext{
${ }^{57}$ Ibíd. P. 25.

${ }^{58}$ Op. Cit. DERRIDA, Jacques. La escritura y la diferencia. P. 397.
} 
habituándonos a transitar sus márgenes como posibles oportunidades coyunturales de intentar lo que podría (o puede) haber sido de otro modo, históricamente distinto. Esto puede verse representado, genéricamente, con el pasaje de la octava tesis sobre el concepto de historia de Benjamin, que afirma que:

La tradición de los oprimidos nos enseña que la regla es el 'estado de excepción' en el que vivimos. Hemos de llegar a un concepto de la historia que le corresponda. Tendremos entonces en mientes como cometido nuestro provocar el verdadero estado de excepción ${ }^{59}$.

Específicamente, en Benjamin, podemos encontrar que esta distinción, esta posibilidad, se manifiesta claramente en la escucha, como si fuera un susurro a percibir. Un rastro que trona y relampaguea por las tinieblas de la obra, en el lenguaje del original, que no se encuentra a simple vista, que es pensado en suspenso como emergencia intempestiva de aquello absolutamente otro del presente, y se manifiesta en el roce, en el toque de los lenguajes que implica la forma de la traducción. Esto también lo encontramos, en movimiento análogo y a merced del lector, en la primera tesis sobre el concepto de historia, con el "enano jorobado"60 maestro en ajedrez y su presencia oculta, representando a la teología como necesidad para la redención en la historia, o bien, cuando en la séptima tesis llama a "pasarle a la historia el cepillo a contrapelo" ${ }^{16}$; desde allí nos está invitando a dejar al descubierto la falla, lo que agrieta el sentido del relato establecido, el punto de fuga en la historia de los vencedores que servirá a la apertura de nuevos sentidos para dicha posibilidad redentora. En este orden de cosas, podemos también identificar por oposición, la aprehensión de un único y clausurado sentido, fruto del trabajo de las "malas traducciones" que no pueden salirse del convencionalismo de la noción burguesa de lenguaje.

Junto a esta noción de supervivencia, no podemos evitar que, similarmente, irrumpa lo que Jacques Derrida reconoce como iterabilidad: esa reiteración que hace perceptible en la escritura a la ausencia como permanencia más allá de la presencia. Y estrechamente ligada a

\footnotetext{
${ }^{59}$ Op. Cit. BENJAMIN, Walter. Conceptos de filosofía de la historia. P. 9.

${ }^{60}$ Ibíd. P. 5.

${ }^{61}$ Ibíd. P. 9.
} 
ésta, el concepto de citacionalidad, que asiste a engendrar infinitamente nuevos contextos ${ }^{62}$, rompiendo con la posibilidad de pensar contextos acabados, clausurados sobre sí mismos que agoten la superabundancia de sentidos. Así, en la escritura, como organizadora del lenguaje, de un sistema de huellas infinitas que manifiestan la ausencia, la diferencia de la presencia o, mejor dicho, la differance, van quedando a la vista los puntos de fuga: aperturas infinitas que permiten leer lo que nunca fue escrito, que muestran que la escritura es una práctica sin fin de devenir lo otro que aún no es.

En este sentido, para Adorno, podemos pensar lo nuevo como posibilidad creativa y subversiva que la historia permite sólo allí donde es entendida como naturaleza, como tránsito de lo finito y perecedero, que puede irrumpir en la alienante historia de lo sido (esa que se impone como inexorable) del mundo sociocultural cognoscible que se presenta como "natural" al cobrar sentido de los sujetos, pero que es incomprensible para ellos en tanto que perenne. Eso que los aliena y recae sobre sus espaldas con todo el peso y la violencia de la identidad. Así, lo nuevo, mediante su negatividad, servirá a la movilización de lo particular como resistencia a la absolutización de la historia de lo sido, cediendo de esta manera la universalidad a la realización de los sujetos, terminando con la opresión de la totalidad a manos de una cierta atracción por lo otro. Movimiento que quiere la reconciliación, es decir, el acogimiento de la naturaleza, de su transitoriedad, por parte del hombre y, que es posible dada una "comprensión" del "carácter procesual" histórico de la obra de arte, es decir, de su (ser que es) devenir como infinita reflexión ${ }^{63}$.

En suma, para nuestros autores, parece haber algo en suspenso en la obra de arte, que se quiere salir de ella, y que el/los sujeto/s, en disposición, puede/n y debe/n querer hacer salir de ella como sentido posible, dejándolo al descubierto, en tanto que posible irrupción en una historia entendida como transitoriedad.

\footnotetext{
${ }^{62}$ Dice acerca del signo como marca en la escritura: "en posibilidad de funcionamiento separado, en un cierto punto, de su querer-decir 'original' y de su pertenencia a un contexto saturable y obligatorio". Op. Cit. DERRIDA, Jacques. Firma, acontecimiento, contexto. P. 15.

${ }^{63}$ Op. Cit. ALBRECHT, Wellmer. "¿Podemos aún hoy aprender algo de la estética de Adorno?". P. 25.
} 


\section{El arte y lo imposible: significación y contingencia}

Pues bien, respecto de la historia y más allá de ella, estos autores dan un lugar central a la contingencia; cuestionando todo absolutismo, pero sin caer en un relativismo extremo. Es decir, por un lado, al ser la obra de arte un producto histórico-crítico ligado a un contexto social, nuestros filósofos realizan un llamado a concientizar que no debería haber una relativización y una frivolización de ella, como aprovechamiento para controlar cualquier peligro de reacción política, utilizándola como herramienta ideológica al servicio de la legitimación de determinadas formas políticas dominantes. En esta dirección va la tensión que indicó Benjamin acerca de la industria cinematográfica sonora que puede atrofiar la imaginación de los individuos y alentar su automatización y alienación, a la vez que también puede propiciar una cierta crítica de las condiciones sociales y políticas dominantes. Justamente, conocemos la denuncia de esa alienación por el concepto de estetización de la política $^{64}$ y el consecuente embellecimiento de la guerra que propugnó (o propugna) el fascismo, pero también la posibilidad de interrupción crítica que existió (o existe) a manos del cine de vanguardia.

El arte debe estar al alcance de los individuos y, propiciando su democratización (tanto estética, como técnicamente), alentar un ejercicio reflexivo y subversivo. No debe delimitar el ámbito y la conducta de los individuos, sumando a su automatismo, sino que debe correr esos límites, debe servir a pensar impensables. En este aspecto, la obra, al exceder toda comprensión posible como aprehensión de un sentido final, último, y dejando, en tal caso, siempre un resto de significación, imposibilita toda absolutización y totalización, propendiendo a una apertura posible de sentidos que llaman a lo otro que podría haber sido distinto, como devenir incesante. Este, su provecho, implica un ejercicio reflexivo propiciado por el arte. En tal sentido, tanto la deconstrucción derrideana como la traducción benjaminiana, con las cuales la escritura no se agota en lo escrito, alientan su infinitud, su sobrevida, su transformación. He aquí, a las claras, un poderío subversivo del arte.

Análogamente, la noción adorniana de negatividad del arte inherente a lo nuevo, que supone la soberanía del arte, la cual se sirve del concepto como posibilidad de subversión de

\footnotetext{
${ }^{64}$ Idea que desarrolla Benjamin en su ensayo: La obra de arte en la época de su reproductibilidad técnica, a la cual contrapone la "politización del arte". Op. Cit. BENJAMIN, Walter. Conceptos de filosofía de la historia. Pp. 95-128 ("La obra de arte en la época de su reproductibilidad técnica") y, específicamente, en (su epílogo o "Estética de la guerra") 128-130.
} 
otros discursos, es utopía. Y en el despliegue de su poder subversivo, en pos de salvar lo noidéntico de la identidad con el todo social que pervive en el sujeto a través del cual violenta lo múltiple, incurre en su paradoja. De esta forma, al poner una contrapresión a esa identidad que violenta lo múltiple, además de dejar de manifiesto la irreconciliación, también hace violencia a la pluralidad, presentándose sin embargo, como si no lo hiciera, como reconciliación. En este movimiento, "el objeto estético no es simplemente un significante formado con vistas a una significación, sino una perpetua oscilación entre significante y material bruto, que excede a toda comprensión" ${ }^{\prime 65}$. Así, hay un exceso que queda de manifiesto en el fracaso de la comprensión automática ${ }^{66}$ debido a la falta de un contexto cerrado sobre sí, y que puede ser reconvertido a través de un acto de citación como determinación del material bruto, pero no en forma acabada sino, quedando fuera de él, diversos caracteres significativos. En estos términos, el objeto estético excede a su comprensión automática como sobreabundancia, como sobredeterminación en la experiencia. Y así, no puede pensarse un sentido último como resultado, disolviéndose todo automatismo de la comprensión, y abriendo el panorama de la significación. En definitiva, si volvemos sobre estas líneas, nos encontramos nuevamente con el claro ejemplo de la escritura.

\section{Conclusiones: el arte como posibilidad política y como continente de lo político}

De lo expuesto, es lícito concluir que el arte no se abstrae de los problemas políticos, sino que puede comportar lo político. La tematización de estos autores acerca de su potencial crítico y las posibilidades alternativas que albergan las expresiones artísticas como productos socioculturales, son prueba cabal de su actualidad como herramienta/s de transformación social y política. Sin embargo, si bien pueden pensarse como herramientas poderosas en el ámbito de la política, no puede establecerse una continuidad necesaria entre su potencia crítica y la acción propia de la praxis política. Es decir: que la acción política puede ser correlato de dicha potencia está a salvo de toda duda, pero lo que no se puede tener es una garantía absoluta de que así sea.

Por lo tanto, el arte puede contribuir al cambio social, puede vehiculizar las prácticas que pretendan reorganizar las relaciones de poder y las fuerzas propias de la dimensión de lo

\footnotetext{
${ }^{65}$ Op. Cit. MENKE, Christoph. La soberanía del arte. La experiencia estética según Adorno y Derrida. P. 93.

${ }^{66}$ Ibíd. P. 93.
} 
político en una sociedad determinada, en un tiempo y lugar específicos. Para eso, basta pensar en los movimientos de reflexión crítica propuestos por los autores que, ya sean de tipo deconstructivo o tengan la forma de la traducción benjaminiana o de la reconciliación adorniana, permiten meditar alternativas de acción política para propiciar transformaciones sociales que se fundan en las experiencias radicales de lo otro como posible porvenir. Entonces, se puede afirmar, como Wellmer lo hace a propósito de Adorno, que: las obras de arte no sólo pueden cuestionar "modos de ver el mundo", sino que "pueden dar lugar a nuevos espacios de experiencia, verdad y articulación"67, abriendo discursos y nuevas experiencias sociales y políticas.

De esta manera, los autores proponen comenzar a entender y por qué no a reelaborar las estructuras y las categorías legítimas de la tradición occidental en otros términos y así deslegitimarlas, poniendo en cuestión lo establecido, en pos de criticar los lugares comunes de opresión y exclusión que propician. Parece entrar en juego, en estas concepciones de lo estético, un compromiso por lo distinto que asiste a la posibilidad de trastocar o subvertir los tantos de lo económico, social y por tanto, políticamente instituido en nuestras sociedades contemporáneas.

En este sentido, la actualidad de la potencia crítica del arte, invita, propositivamente, a una praxis y a una reflexión política que, o bien puede servirse de ella o bien puede inspirarse en ella. Así, se puede afirmar que una democratización de la experiencia estética, tanto a modo de práctica como de reflexión crítica, y gracias a su poder subversivo, puede tener un efecto multiplicador sobre la creatividad y reflexión individuales, a los fines de que, en una determinada sociedad, los actores sociales en general, puedan repensar y modificar ciertas prácticas institucionalizadas y determinadas instituciones sociales y políticas establecidas. Asimismo, su proliferación puede tener un correlato directo en una dinamización política del ámbito social que incremente la participación en lo público.

En suma, tanto Benjamin como Adorno y Derrida, allanaron el terreno desde la perspectiva de una teoría estético-política, para comenzar a comprender que, contra todo argumento despolitizador ${ }^{68}$ que presente lo político como unidad refiriendo a un criterio

\footnotetext{
${ }^{67}$ Op. Cit. ALBRECHT, Wellmer. "¿Podemos aún hoy aprender algo de la estética de Adorno?". P. 30.

${ }^{68}$ Pensemos en este caso, como discursos que apuntan a conservar lo establecido (instituciones tradicionales político-jurídicas) como situación políticamente ideal; asimismo, aquellos que alientan perspectivas teleológicas que persiguen situaciones de tal índole, donde tanto la política como lo político sean, espacial y temporalmente, neutralizados.
} 
totalizante, éste, es un constante movimiento que no pretende desplegar un absoluto, que no se dirige un fin último, sino que es una práctica sin fin la cual, en detrimento de toda objetividad social, se encuentra siempre abierta a desplegar nuevas prácticas y formas posibles de participación e identidades políticas, y encuentra un elemento dinamizador en la expresión y la reflexión estéticas.

\section{Bibliografía}

- $\mathrm{ABADI}$, Florencia. "La teoría de la crítica de arte: la lectura de Benjamin del romanticismo alemán". En: Boletín de Estética (CIF). № 12. Buenos Aires, 2009

- ADORNO, Theodor. Teoría Estética. Madrid, Akal, 2004.

- ALBRECHT, Wellmer. "¿Podemos aún hoy aprender algo de la estética de Adorno?". En: Boletín de Estética. $\mathrm{N}^{\circ} 11,2009$

- ALBRECHT, Wellmer. "¿Podemos aún hoy aprender algo de la estética de Adorno?". En: Boletín de Estética (CIF). N 11, 2009

- ALBRECHT, Wellmer. Sobre la dialéctica de modernidad y posmodernidad. La crítica de la razón después de Adorno. Madrid, Visor, 1993

- BENJAMIN, Walter. Conceptos de filosofía de la historia. Buenos Aires, Agebe, 2011

- COLLINGWOOD-SELBY, Elizabeth. Walter Benjamin: La lengua del exilio. Universidad de Chile, 1997. [Tesis doctoral]. Dirección: https://www.yumpu.com/es/document/view/28627519/walter-benjamin-la-lengua-del-exiliouniversidad-de-chile

- DERRIDA, Jacques. De la gramatología. México, Siglo XXI, 1986

- $\quad$--.-. Firma, acontecimiento, contexto. Universidad de Montreal, 1971. P. 9. [Ponencia]. Dirección: http://www.ddooss.org/articulos/textos/derrida firma.pdf.

- DERRIDA, Jacques. La escritura y la diferencia. Barcelona, Anthropos, 1989

- MENKE, Christoph. La soberanía del arte. La experiencia estética según Adorno y Derrida. Madrid, Visor, 1997

- MOUfFe, Chantal. En torno a lo político. Buenos Aires, Fondo de Cultura Económica, 2011

- SCHWARZBOCK, Silvia. Adorno y lo político. Buenos Aires, Prometeo, 2008 